\title{
A cidade de Londres nas canções da experiência de William Blake: uma interpretação das transformações ocorridas na sociedade industrial inglesa nas últimas décadas do século XVIII.
}

The city of London on the songs of experience from William Blake: an interpretation of social changes occurred in english industrial society in the last decades of the eighteenth century

\section{Flavia Maris Gil Duarte*}

\section{RESUMO}

Este artigo pretende analisar algumas das transformações sociais ocorridas na Inglaterra nas últimas décadas do século XVIII a partir do poema London presente na obra Songs of Innocence and of Experience do poeta e gravador William Blake, autor inserido no movimento romântico inglês. Sua obra foi marcada, como um todo, pelo pensamento místico culminando na criação de uma cosmogonia capaz de explicar, segundo o autor, a condição humana. Podemos perceber nos poemas de William Blake sua visão sobre a época em que viveu, sua interpretação da realidade pode elucidar algumas das experiências da sociedade inglesa na transição entre os séculos XVIII e XIX: que integrava o processo de industrialização, o crescente deslocamento da razão como centro do pensamento e ouvia os ecos da revolução francesa. Songs of Innocence and of Experience contém os fundamentos do pensamento desenvolvido ao longo das obras posteriores de William Blake, expressa as transformações sociais por ele vivenciadas num universo onde política, religião e arte se entrelaçam na construção de uma interpretação peculiar da formação da sociedade industrial moderna.

Palavras-chave: William Blake. Religiosidade. Sociedade Industrial. Literatura. Romantismo.

\footnotetext{
* Mestre em História Social pelo Programa de Pós-Graduação em História Social - Universidade Estadual de Londrina - UEL, 2014.
} 


\begin{abstract}
This article intends to analyze some of the social changes in England in the last decades of the Eighteenth century from the poem in London that is in the work Songs of Innocence and of Experience of the poet and engraver William Blake - an author inserted in the English Romantic movement. His work has been marked, as a whole, by mystical thought culminating in the creation of a cosmogony able to explain, according to the author, the human condition. We can notice in the poems of William Blake his vision about the time in which he lived, his interpretation of reality can elucidate some of the experiences of English society in the transition between the Eighteenth and Nineteenth centuries: that was part of the process of industrialization, the increasing displacement of reason as center of thought and heard the echoes of the French Revolution. Songs of Innocence and of Experience contains the foundations of thought developed over the later works of William Blake - expresses social transformations he lived in a universe where politics, religion and art intertwine in building a peculiar interpretation of the formation of modern industrial society.
\end{abstract}

Keyword: William Blake. Religiousness. Industrial Society. Literature. Romanticism.

Em 1757, mesmo ano em que nasceu William Blake, Abbé Le Blanc, escreveu algumas de suas impressões ao visitar Londres, ele destacou a sua magnitude, pois não se tratava, certamente, de uma cidade bonita, "[...] e era mesmo possível que o estrangeiro a julgasse desagradável. 'Depois que tiverdes visto a Itália', [...] 'nada vereis nos edifícios de Londres que vos cause grande prazer'. A cidade na verdade só assombra por sua grandeza.' [...]" (HOBSBAWM, 2009, p.24). Apesar de algumas tentativas em controlar a construção de moradias entre os pobres, ainda no início do século XVIII, eles chegavam à metrópole num número cada vez maior. Era fato que muitas das pessoas que habitavam a cidade sem um emprego estável tinham de procurar manter-se por meios ilícitos, a ponto de no final do século XVIII, algumas estimativas sobre as classes mal vistas pela sociedade, apresentarem dados significativos. Na virada do século estimou-se que havia em Londres cerca de $\mathbf{5 0 . 0 0 0}$ prostitutas, mais de 5.000 taberneiros e 10.000 ladrões. Incluindo nesses números outros personagens das classes criminosas, tais como, receptadores de propriedades roubadas, falsos moedeiros, jogadores, agentes lotéricos, lojistas fraudulentos, parasitas às margens do rio, e personalidades pitorescas como garotos da sarjeta, caçadores de brigas, marreteiros, marroquinos, cocheiros de ocasião ou menestréis ambulantes, haveria cerca de $\mathbf{1 1 5 . 0 0 0}$ indivíduos, sendo que a população da cidade ainda era inferior a 1 milhão de habitantes (THOMPSON, 2004, v.1, p.57).

No poema London de Songs of Experience (1794) foi construída uma imagem da capital inglesa através da visão de William Blake (1757-1827). Por intermédio da poesia e das artes visuais, Blake dialogava com a sociedade inglesa na transição dos séculos XVIII e XIX. Em sua obra podemos perceber qual era a visão do artista sobre a cidade de Londres, e sobre outras questões como o Romantismo, a arte, os ecos políticos e sociais da Revolução 
Francesa, as dissidências religiosas protestantes, o uso do tempo e da razão, sobre os trabalhadores adultos e os pequenos limpadores de chaminés que caminhavam por entre a neve. Esse caleidoscópio de eventos, pensamentos e pessoas foi observado por Blake na construção de sua interpretação sobre a sociedade moderna industrial.

Podemos encontrar os fundamentos do pensamento desenvolvido nos trabalhos posteriores de William Blake em Songs of Innocence and of Experience. Diferente das artes visuais, na qual recebeu um treinamento técnico, a formação literária de William Blake ocorreu de maneira autodidata através de uma combinação de leituras das quais se destacam a Bíblia e o poeta John Milton. Ao longo de sua vida Blake buscou o reconhecimento de sua obra como genuinamente artística, sendo os principais elementos dessa busca sua capacidade inventiva e a rejeição às instituições formais de ensino. Essa rejeição ao academicismo, talvez tenha sido motivada pelo surgimento, no período em que Blake viveu, de uma forte distinção entre o trabalho dos artistas, que seriam genuinamente criativos, e dos artesãos, dentre os quais podemos incluir os gravadores, vistos como meros comerciantes vulgares (ALVES, 2007; p. 67).

Em seu trabalho, Blake buscou a superação da divisão entre o trabalho do tipógrafo e do gravador, unindo palavras e imagens. ${ }^{1} \mathrm{Em} 1788$ desenvolveu um método ao qual denominou Illuminated Printing, por meio dele compôs os seus Illuminated Books, sendo um deles "Songs of Innocence and of Experience", no qual destacamos o poema intitulado London. ${ }^{2}$

Peter Linebaugh, no artigo "Todas as montanhas atlânticas estremeceram", tomou de empréstimo a expressão "montanhas atlânticas", de William Blake, para intitular seu artigo. De acordo com Linebaugh, esta seria uma expressão que sintetizaria as duas décadas revolucionárias na transição entre os séculos XVIII e XIX, nas quais eventos profundos abalaram diferentes nações e atingiram os quatro cantos do Atlântico. Blake considerava que as contradições que se fizeram sentir neste período apontavam para uma humanidade

\footnotetext{
${ }^{1}$ As obras que foram compostas por poemas e imagens gravadas segundo esse método ficaram conhecidas como Illuminated Books. Os primeiros livros que receberam essa denominação, embora ainda não tenham sido gravados da mesma forma que suas obras posteriores, foram produzidos em 1788: All Religions are One e There is No Natural Religion. Nesses trabalhos, Blake gravava texto e imagem nas pranchas de cobre que depois seriam coloridos em aquarela, sendo que o artista variava a composição das cores ou mesmo das pranchas em diferentes versões dos mesmos trabalhos. A isto é que se chama arte composta. Durante a vida de Blake, esses Illuminated Books nunca foram produzidos em larga escala, pois Blake os elaborava de forma lenta e minuciosa e em caráter mais artesanal. ALVES, Andréa Lima. "A Oposição é Verdadeira Amizade": Imagem poética e pictórica no livro O Matrimônio do Céu e do Inferno de William Blake. Campinas-SP, 2001. 216 p. Dissertação de Mestrado. Universidade Estadual de Campinas, Instituto de Estudos da Linguagem. (pp. 17-18). Neles, ele não apenas buscou superar a divisão especializada do trabalho no mercado editorial, como também fez essa combinação entre texto e imagem de uma forma singular. As imagens que acompanham os textos nem sempre os representam de maneira explícita, ou não apresentam situações e personagens narrados diretamente ligados ao texto.

${ }^{2}$ Songs of Innocence foi produzida em 1789 e publicada de forma independente até 1794 quando Blake torna esta obra complementar a Songs of Experience. Após essa data não existem cópias independentes dessas obras, e devemos, portanto, considerá-las como uma só.
} 
dividida pela "opressão, pela ciência, como um meio de conquista, e por 'leis' de economia política” (LINEBAUGH, 1993, p. 8). O artista se envolveu ativamente nas grandes transformações daquele período, foi amigo do revolucionário Tom Paine, sendo também processado por sedição. Ele, porém, não estava sozinho, e é necessário lembrar que diversos autores do romantismo inglês se comprometeram com as transformações sociais e políticas de seu tempo: William Wordsworth escreveu panfletos políticos, Coleridge se dedicou ao jornalismo político e à filosofia social, Shelley distribuiu manifestos nas ruas, Southey foi um constante comentarista político, Byron falou em comícios e morreu como participante voluntário em uma guerra política. Essas atividades não podiam ser separadas da experiência da qual nasciam os poemas (WILLIAMS, 1969, p. 53-54).

É possível dizer que o surgimento do Romantismo foi associado ao desenvolvimento da modernidade, aqui considerada como fruto de um processo intrínseco ao próprio desenvolvimento do capitalismo, que teve início no século XVII, culminando nos séculos XVIII e XIX. O processo foi desencadeado a partir da renascença e da reforma protestante, e o romantismo surge, desse modo, “[...] quando as tendências em ação, há muito tempo, se transformam em sistema, quando são criadas as bases da indústria moderna e se concretiza o domínio do mercado sobre o conjunto da vida social [...]" (LÖWY e SAYRE, 1995, p. 77). Baumer (1990, p. 23) considerou também o romantismo como o primeiro grande protesto contra a modernidade, definida por ele como a civilização científico-racional que começou a desenvolver-se no século XVII e que assumiu uma grande dimensão no século XVIII.

Esse fenômeno provocou um profundo sentido de vazio metafísico que os românticos buscaram preencher de diferentes formas e pensamentos religiosos. Para os românticos os homens haviam perdido as suas capacidades metafísicas e religiosas e precisavam recuperálas. Como alcançariam este objetivo? Como reaver a fé? Em busca de respostas a estas questões, muitos românticos se voltaram para o catolicismo; outros permaneceram protestantes, ainda que também passassem a ver a sua religião de uma forma diferente, idealizada. Outros ainda, dentre eles William Blake, abandonaram as formas instituídas de religião e inventaram novos deuses e novas mitologias (BAUMER, 1990, p. 31-32). Muito do pensamento romântico relacionou-se a uma nova ideia de natureza, ou mesmo de Deus. Thomas Carlyle, por exemplo, considerou que o erro dos filósofos do século XVIII, foi justamente este desencantamento com relação à natureza e sua dimensão sobrenatural:

Que o Sobrenatural não difere do Natural é uma grande Verdade que o século passado (especialmente em França) se propôs demonstrar. Contudo, os Filósofos estavam errados, porque, em vez de elevarem o natural ao sobrenatural, esforçaram-se por afundar o sobrenatural no natural. $O$ ponto principal de todo o meu pensamento é fazer não a última dessas coisas, mas a primeira. [grifos no original] (CARLYLE, In: BAUMER,1990, p. 31) 
Coleridge, por sua vez, mostrou uma natureza mágica e sagrada em A Balada do Velho Marinheiro, e atentou para essa dimensão de sacralidade, da qual falou Carlyle, em alguns de seus versos nessa obra. Nesse poema Coleridge apresenta um marinheiro castigado por matar um Albatroz, ave símbolo de boa sorte e é condenado a perambular eternamente como um morto vivo contando de tempos em tempos o mal que lhe ocorrera. A intenção do marinheiro ao contar a sua história era "ensinar, através do próprio exemplo, o amor e a reverência por todas as criaturas que Deus criou e que ama" (COLERIDGE, In: CARVALHO, 2006, p. 104).

O romantismo foi responsável por despertar uma renovação religiosa e, dentre as várias formas que esta renovação adquiriu, observamos a emergência do que muitos autores denominaram misticismo religioso. A valorização da religião no pensamento romântico era inspirada por um profundo sentido do vazio metafísico, decorrente do pensamento Iluminista. Deus havia se tornado inexistente ou periférico, limitado às suas próprias leis racionais para os filósofos que "esforçaram-se por afundar o sobrenatural no natural". 0 conhecimento proveniente apenas da matéria deveria ser, segundo Blake, descartado como falso, pois somente Deus forneceria um saber verdadeiro. O ser humano, a natureza e tudo o que ela contém seriam sagrados e a frase recorrente "tudo o que vive é sagrado", é reveladora em relação a esse pensamento do poeta.

As leituras e experiências religiosas peculiares de William Blake não foram fruto apenas de sua imaginação artística, mas também de sua experiência e do seu contato com as dissidências religiosas que floresciam no período em que ele viveu. Especialmente a partir do século XVII, a bíblia começou a servir de fundamento para diferentes propósitos, algumas vezes contraditórios entre si. Christopher Hill foi um dos primeiros historiadores a mostrar que durante várias décadas do século XVII foi sendo formada uma tradição que teve como uma de suas bases as dissidências religiosas e foi responsável por várias revoltas populares nesse período (HILL, 2001, p. 29).

A bíblia, vista como fundamento de toda a cultura inglesa deste período, não pode ser interpretada em termos estritamente religiosos, pois nela os homens buscaram respostas para questões das mais diferentes ordens (HILL, 2001, p. 9). Num mundo em que a religião se fazia presente no cotidiano dos homens não podemos pensá-la como um elemento que encobria ou justificava acontecimentos concretos, mas como uma parte intrínseca da vida cotidiana. Semelhante ao pensamento de Hill e adicionando a ele outros elementos E. P. Thompson fez a sua leitura das dissidências religiosas afirmando que este envolvimento entre religião e política fazia parte de uma tradição mais ampla ligada à dissidência religiosa entre as classes populares e os intelectuais na Inglaterra, mostrando o quanto estas eram atividades que não estavam separadas para muitos daqueles homens (THOMPSON, 2004, v.1, p.23). Thompson ainda afirmou que: 
A própria anarquia da antiga Dissidência, com seus cismas e igrejas autogeridas, significava que podiam surgir subitamente as idéias mais inesperadas e menos ortodoxas [...] A história intelectual da dissidência é composta de choques, cismas, mutações; muitas vezes sentem-se nela os germes adormecidos do radicalismo político, prontos para germinar logo que semeados num contexto social promissor e favorável [grifo nosso] (THOMPSON, 2004, v.1, p. 36).

Podemos considerar o período que abrange o final do século XVIII e início do século XIX como um contexto social promissor e favorável ao surgimento de dissidências religiosas. Nesse período, em que se articulavam novas maneiras de pensar, trabalhar e sentir, a dissidência religiosa tomou força, atendendo as expectativas de determinadas classes sociais que não encontravam na religião oficial uma doutrina que voltasse os olhos para elas e suas necessidades. ${ }^{3} \mathrm{Na}$ Inglaterra, o protestantismo foi antes de tudo um campo religioso formado em torno dos interesses dos aristocratas, da pequena nobreza e das classes médias, ${ }^{4}$ e seu objetivo ao atingir as classes pobres foi bem definido por Burke, em 1795. Dos pobres, de acordo com Burke, o protestantismo esperava "paciência, trabalho, sobriedade, frugalidade e religião é o que deve se recomendar a eles; tudo mais é pura fraude" (THOMPSON, 2004, v.1, p. 59). Dessa forma, podemos perceber que, menos que fiéis obedientes, o protestantismo visava pobres ajuizados, trabalhadores e disciplinados, garantindo assim a estabilidade social. As seitas dissidentes, ao contrário, eram percebidas como libertadoras das massas dos grilhões daquela sociedade e por isto o idioma da religião passou a ser visto como perigoso e a "bíblia um documento altamente incendiário" (HOBSBAWM, 2005, p. 308).

Por dissidência entendemos, tal como definido por Thompson, um conjunto de muitas seitas desvinculadas da igreja anglicana, com tendências intelectuais, milenaristas e teológicas, que surgiram em diferentes meios sociais como questionamento ao anglicanismo; segundo o autor, "[...] na complexidade de seitas concorrentes e capelas divididas temos o viveiro para as variantes da cultura operária do século XIX" (THOMPSON, 2004, v.1, p.52). Entre as diferentes formas de ler e interpretar a bíblia, que foram também estimuladas pela tradução e publicação do livro em diferentes línguas vernáculas, podemos destacar duas delas. A primeira consistia em utilizar a narrativa bíblica atribuindo-lhe um sentido próprio, como observamos, por exemplo, no pensamento dissidente lido por Blake. $\mathrm{E}$ a segunda que consistia em mostrar que a bíblia não era infalível, criticando seus

\footnotetext{
${ }^{3}$ Por religião oficial ou igreja no trabalho de William Blake entende-se, conforme considerado por Alcides Cardoso dos Santos, "[...] a Igreja com o suporte político e econômico das classes dominantes e do Estado [...]" SANTOS, Alcídes Cardoso dos. Visões de William Blake: imagens e palavras em Jerusalém a Emanação do Gigante Albion. Campinas-SP: Editora da Unicamp, 2009. (p 19).

${ }^{4}$ A igreja anglicana formou-se a partir de uma ruptura com o papado, mas como lembrou C. Hill, foi organizada "de cima para baixo" pelo rei Henrique VIII e o seu ministro Thomas Cromwell em 1530. (HILL, 2001; p. 47).
} 
fundamentos e mostrando que ela não era um manual de conduta inquestionável (HILL, 2001, p. 256).

O trabalho de William Blake é repleto de referências bíblicas, que aparecem através de sua interpretação peculiar, conforme o próprio artista afirmou:

\author{
Ambos lêem a Bíblia dia \& noite \\ Mas eles lêem preto onde Eu leio branco \\ (BLAKE, In: ERDMAN, 1988, p. 524) ${ }^{5}$
}

Christopher Hill observou que Blake admitia que todo o seu conhecimento estava contido na Bíblia, porém sua leitura se assemelhava à dos ranters, que rejeitavam o sentido literal das Escrituras, compreendendo-a num sentido espiritual (HILL, 2003, p.608), que podemos compreender aqui como uma leitura vinculada às experiências vividas. A bíblia, para Blake, era uma união entre arte e profecia e por isto ele considerava que tanto a bíblia quanto a história seriam "mito poéticas". Ele comparava as escrituras a um épico, que desempenhava um papel também na formação da cultura nacional, sendo em parte uma história lendária e em parte visão profética. Assim, a bíblia foi por ele considerada como o produto histórico de uma tradição visionária, mostrando estágios comuns nos acontecimentos históricos segundo a religião. Podemos dizer que a Bíblia, para Blake, "[...] registra uma contínua remodelagem das primeiras visões, que a seguir tornam-se mais explicitamente proféticas, até as confusas lendas de um povo ignorado tomam a forma de uma visão cíclica completa de queda, redenção e apocalipse. [...]" (FRYE, 1990, p. 317). ${ }^{6}$

Na complexidade das diversas leituras bíblicas, uma questão se apresenta. Em qual tradição podemos localizar o pensamento de William Blake? Certo é que a bíblia constituiu a sua principal leitura, mas foi lida de uma forma peculiar que se aproximava das leituras dos dissidentes radicais. Para a elaboração deste trabalho, tomei como referência a tradição antinomista, devido a sua ideia de rejeição às leis, algo que dentro do contexto bíblico pode ser interpretado como a rejeição às leis morais. São de grande relevância também o muggletonianismo e a igreja swedenborgiana da Nova Jerusalém, pois existem muitas referências a elas no trabalho de William Blake, seja de forma aberta, como a crítica de Blake a Swedenborg, ou indireta, como é o caso do vocabulário e imagística comuns ao muggletonianismo que são encontrados nas obras de Blake.

A palavra "antinomismo" significa, em sua origem, "contra a lei". Encontramos algumas das bases para este pensamento na bíblia, por exemplo, em Gálatas, "Pois toda a Lei encontra

\footnotetext{
${ }^{5}$ Both read the Bible day \& night / But thou readst black where I read white.

${ }^{6}[\ldots]$ It records a continuous reshaping of the earlier and more primitive visions, and as it goes on it becomes more explicitly prophetic, until the confused legends of an obscure people take the form of the full cyclic vision of fall, redemption and apocalypse [...]
} 
a sua plenitude num só mandamento: ‘Ame o seu próximo como a si mesmo'." (GÁLATAS 5, 14). Também em Romanos, "agora, morrendo para aquilo que nos aprisionava, fomos libertos da Lei, a fim de servimos sob o regime novo do Espírito, e não mais sob o regime da letra." (ROMANOS 7, 6). Uma questão é central no pensamento antinomista: como um homem seria salvo, através da graça e fé ou das obras? Temos de um lado doutrinas que pregam as obras e boas condutas pautadas sobre as leis morais, especialmente os dez mandamentos, e de outro, o antinomismo. Os antinomistas professavam uma religião que não se pautava sobre a moralidade. Havia, para eles um pensamento implícito de que os homens poderiam pecar o quanto quisessem, porque embora Deus pudesse odiar o pecado tinha, porém, prazer em perdoá-lo (THOMPSON, 1994; p. 58). Para Calvino, através da ideia de predestinação, o homem seria salvo não importando o que ele fizesse. Para os antinomistas a ênfase não estaria nos eleitos, mas nos crentes, em sua fé. Nesse sentido, a origem do antinomismo pode ser encontrada no pensamento calvinista, e seria como um calvinismo das classes populares. (THOMPSON, 1994; p. 17). A ideia de predestinação era acompanhada da crença na santidade dos eleitos, de sua pureza de coração.

O "Matrimônio do Céu e do Inferno" de Blake, por exemplo, pode ser considerada como uma sátira antinomista voltada contra os swedenborgianos. (THOMPSON, 1994; p. 19). Blake rejeitou, porém a ideia de predestinação e, a parte do antinomismo presente no trabalho de Blake foi a rejeição às leis morais. $\mathrm{O}$ antinomismo constituiu uma forma de quebrar 0 moralismo e procurar novas possibilidades de conduta e de pensamento religioso. Influências antinomistas são encontradas, por exemplo, nos ranters e nos muggletonianos.

Os muggletonianos recusaram o panteísmo dos ranters ${ }^{7}$ e dos behmenistas ${ }^{8}$ e o substituíram por uma crença literal em um único Deus/Cristo na imagem de homem, ainda que em outras partes de sua doutrina o muggletonianismo esteja bem próximo destas duas crenças (THOMPSON, 1994; p. 66). Deus seria, para eles, indivisível, sendo a linguagem da trindade (pai, filho, espírito santo) empregada apenas para representar as diferentes manifestações do mesmo ser.

\footnotetext{
${ }^{7}$ Os ranters, assim chamados a partir de uma derivação do verbo to rant (falar demais), surgiram no século XVII, nos tempos da Commonwealth. C. Hill considerou difícil definir de forma precisa em que acreditavam os ranters, devido a diversidade de suas opiniões, (HILL, 2001; p. 204) mas podemos apontar algumas questões chave em seu pensamento. Eles se aproximaram de uma visão panteísta de mundo, observando "Deus no livro de suas criaturas". A partir dessa visão de mundo, tanto mais puro seria o homem quanto mais estivesse em sintonia com a essência divina presente em seu coração. Assim, para o homem puro, todas as coisas seriam puras, de modo que Deus não consideraria as suas ações externas, mas sim as suas intenções, pensamento que eles compreenderam "como uma detestável blasfêmia licenciosa a autorizar os maiores deboches" (HILL, 2001; p. 206). Eles rejeitaram a necessidade de uma igreja oficial, das leis morais, assim como a ideia de pecado. $\mathrm{O}$ único pecado que existiria, para os ranters, seria aquele que o próprio homem julgasse existir.

${ }^{8} \mathrm{O}$ termo behmenista é relativo ao pensamento de Jacob Boehme e seus adeptos. Jacob Boehme (1575-1624) foi um sapateiro alemão, que discutiu sobre misticismo, cabala, gnose, alquimia (especialmente de

Paracelso) e outros pensamentos não ortodoxos em um círculo de amizades que incluiu mercadores, intelectuais e alguns nobres, nos últimos anos de sua vida ele estruturou um sistema teosófico através de uma série de tratados. (THOMPSON, 1994; p. 35).
} 
Reeve e Muggleton foram vistos por seus seguidores como mensageiros de uma "nova era", e dividiram o mundo em três eras. A primeira delas foi considerada a "erada lei" e do "velho testamento", e foi simbolizada pela "água". A segunda foi denominada a "era do evangelho de Jesus" e do "novo testamento", e foi simbolizada pelo "sangue". ${ }^{9}$ A terceira delas a "era do poder" [the age of commision] e dos escritos proféticos de Reeve e Muggleton, foi considerada a "era do espírito". A partir desse último momento, a "nova era" com sua correspondente imagem da "Nova Jerusalém" teve início para os fiéis, que viram a si mesmos como "santos" ou como homens "marcados" para sua redenção (THOMPSON, 1994; p. 70).

O mundo também foi compreendido por eles através de princípios "contrários". Os "contrários", para os muggletonianos, não eram entendidos como "os princípios contrários" de Blake. Eles possuíam antes um tom maniqueísta unindo princípios opostos, um material (e mal) e outro espiritual e divino, que configuravam pares opostos como Deus/Natureza, Espírito/Matéria, Fé/Razão. Para os muggletonianos, o mal só existia pela permissão de Deus, pois para que os homens verdadeiramente conhecessem a luz necessitavam observar seu contraste com as trevas. Esses contrários, razão e fé, existiriam na sua visão dentro do homem desde a "queda" (THOMPSON, 1994; p. 71-72). De maneira similar a outras doutrinas que acreditaram na predestinação, seus fiéis se identificassem com o princípio divino, possuindo "o selo da salvação estampado em suas almas". E se os fiéis muggletonianos se identificaram como homens santos, seus oponentes, incluindo reis, magistrados, e sacerdotes foram identificados como a "semente ou descendência do demônio".

Blake acabou rejeitando posteriormente muitas das ideias de Swedenborg, porém é inegável sua importância na composição dos trabalhos do artista. De acordo com Thompson, Swedenborg tentou organizar um extraordinário e contraditório grupo de ideias (algumas dos behmenistas) num sistema racional. Na década de 1780, admiradores e leitores de Swedenborg trocavam correspondências e se reuniam para discutir o pensamento teológico do místico sueco. Seu pensamento despertou interesse, no século XVIII, entre diversos grupos interessados em experiências místicas, tais como behmenistas, rosa-cruzes, maçons e entusiastas do mesmerismo e do magnetismo. Este interesse despertado em grupos tão diferentes marcaria também o conflito de ideias nos primeiros cinco anos da Igreja da Nova Jerusalém, organizada segundo os princípios de Swedenbog (THOMPSON, 1994; p. 135).

O mais provável é que o contato de William Blake com o trabalho de Swedenborg tenha ocorrido mais através de dois periódicos editados em 1790, a saber, The New Jerusalem Magazine e The New Magazine of Knowledge Concerning Heaven and Hell. Das obras do próprio Swedenborg temos registro das anotações de Blake sobre três delas: Heaven and Hell, Divine Love and Divine Wisdom e Divine Providence. Notamos a partir das anotações feitas a respeito

${ }^{9}$ O fato de encontrarmos os termos "água" ou "sangue" nas obras proféticas de Blake para se referir ao velho e o novo testamento é um indício do conhecimento e emprego do pensamento muggletoniano em seu trabalho. 
deste último trabalho que o interesse de Blake em Swedenborg havia se transformado em oposição e dessa oposição surgiu o seu "matrimônio do céu e do inferno". O principal ponto de convergência entre o trabalho de Swedenborg e William Blake seria o conceito de "correspondências", que Swedenborg estruturou em "O Céu e o Inferno", mas que pode ser encontrada em inúmeras tradições esotéricas. De acordo com esse pensamento, cada elemento do mundo espiritual encontraria um correspondente no mundo material. Dessa forma, através da leitura de Swedenborg, Blake foi encorajado a objetivar os seus pensamentos como visões ou conversas com espíritos o que o possibilitou ler a bíblia como mito ou parábola.

Ao ler o poema London emerge uma imagem da cidade como um local generalizado de restrições e sofrimentos. Para ter esta percepção não se faz necessário ter conhecimento das concepções visionárias do poeta, ainda que elas estejam implícitas no poema, como observou Thompson: "[...] Todo leitor é capaz, sem a ajuda de um crítico, de ver Londres simultaneamente como a própria cidade de Blake, como uma imagem do estado da sociedade da Inglaterra e, como uma imagem da condição humana. [...]" (THOMPSON, 1994, p. 174) Esta condição humana é compreendida através do poema como um estado particular. Como se pode apreender deste poema, que reproduzimos a seguir:

Em cada rua escriturada em que ando, Onde o Tâmisa escriturado passa, Eu nos rostos que encontro vou notando Os sinais da doença e da desgraça.

Ouço nos gritos que os adultos dão, E nos gritos de medo do inocente, Em cada voz, em cada interdição, As algemas forjadas pela mente

Se o Limpa-Chaminés acaso grita, Assusta a Igreja escura pelos anos; Se o Soldado suspira de desdita, $O$ sangue mancha os muros palacianos.

Mas o que mais à meia noite é ouvido É a rameira a lançar praga fatal, Que estanca o pranto do recém nascido E empesteia a mortalha conjugal. ${ }^{10}$

10 Tradução de Paulo Vizzioli em: BLAKE, William (1757-1827). William Blake: poesia e prosa selecionadas/ Edição bilíngüe. Introdução, seleção, tradução e notas Paulo Vizioli. São Paulo: Nova Alexandria, 1993. (pp. 6263). I Wander thro' each chater'd street, / Near where the chater'd Thames does flow. / And mark in every face I meet / Marks of weakness, marks of woe. // In every cry of every Man, / In every Infants cry of fear, / In every voice: in every ban, / The mind-forg'd manacles I hear // How the Chimney-sweepers cry / Every blackning Church appalls, / And the hapless Soldiers sigh / Runs in blood down Palace walls // But most thro' midnight streets I hear/ How the youthful Harlots curse / Blasts the new-born Infants tear / And blights with plagues the Marriage hearse. 
A cidade em que vivia William Blake era diferente da cidade em que seus pais nasceram, e as mudanças observadas eram vistas como algo estranho e ameaçador. Em London é como se Blake caminhasse pela cidade e mostrasse ao leitor como ele está imerso neste universo urbano, compartilhando um sentimento que, na visão do poeta, seria geral a toda sociedade. A transformação do distanciamento para a proximidade com o meio urbano é marcada pelas conotações de "observar" e "ouvir".

No primeiro verso vemos através dos olhos do autor que se colocou como um observador que perambulava pela cidade, que disse notar em cada rosto encontrado, "Os sinais da doença e da desgraça". Porém, na segunda, terceira e quarta estrofes nós "ouvimos", os gritos dos adultos e do inocente, do limpador de chaminés, o suspiro do soldado e a rameira a lançar pragas e "[...] a transição da visão para o som tem um efeito de reduzir o sentimento de distância ou de alienação do observador de seu objeto no primeiro verso, e nós somos imersos na condição humana através da qual ele caminha [...]" (THOMPSON, 1994, p.187). ${ }^{11}$

Nos primeiros versos do poema, Blake diz notar "os sinais da doença e da desgraça", presentes "Em cada rua escriturada em que ando, / Onde o Tâmisa escriturado passa". As ruas e o Tâmisa "escriturados" demonstram um dos aspectos da emergente sociedade industrial, qual seja, a da crescente restrição dos espaços públicos e o monopólio de determinadas companhias e corporações, limitando cada vez mais o espaço de atuação do indivíduo comum. A palavra charter'd, traduzida como "escriturado", presente nos dois primeiros versos [I Wander thro' each chater'd street, / Near where the chater'd Thames does flow], tem um amplo significado. Ela pode ser referente a documentos formais; relacionar-se aos direitos de uma pessoa num determinado país e pode também ser alusiva aos direitos de um determinado grupo de pessoas ou de uma organização particular. Charter'd é uma alusão a tudo o que é institucionalizado, estabelecido ou "escriturado".

Northrop Frye, considerou que a palavra charter'd foi utilizada no poema com um significado irônico. Ao mesmo tempo em que ela se relaciona aos direitos das pessoas em uma nação, implicando em liberdades, também é relativa aos direitos de grupos ou organizações particulares, e ao privilégio dos direitos de grupos específicos, que implicava na anulação de direitos da maioria das pessoas no país (FRYE, 1990, p. 180-181).

Thompson também considerou o significado irônico da palavra, da seguinte forma:

[...] Uma declaração oficial de liberdade é, simultaneamente, uma

${ }^{11}[\ldots]$ the passage from sight to sound has an effect of reducing the sense of distance or of the alienation of the observer from his object of the first verse, and of immersing us within the human condition through which he walks $[\ldots]$ 
negação dessas liberdades às outras pessoas. Uma lei oficial é algo dado ou concedido; é de grande valia para um grupo com alguma autoridade em particular; não é reivindicada como um direito. $\mathrm{E}$ as liberdades (ou privilégios) conquistadas por pessoas com interesse comum, companhia, corporação ou até mesmo nação exclui os outros do desfrute destas liberdades. Esse tipo de declaração oficial é, em sua natureza, excludente (THOMPSON, 1994; p. 177). ${ }^{12}$

Num primeiro rascunho de London o autor utilizou os termos "rua suja" [dirty street] e "Tâmisa sujo" [dirty Thames] (THOMPSON, 1994, p. 175) ${ }^{13}$ substituindo-os depois, na versão definitiva, por "rua escriturada" [charter'd street] e "Tâmisa escriturado" [charter'd Thames]. A ideia de um rio e ruas sujas na cidade era uma imagem clara no final do século XVIII, porém a ideia de registro possui a conotação de uma cidade organizada sobre o comércio. Sob este paradigma, Blake observou na cidade um novo fator, que não era composto pelo tumulto, barulho ou um grande problema visto por observadores anteriores e outros contemporâneos a ele, este novo fator era percebido como algo organizado, um estado mental sistemático (WILLIAMS, 1989, p. 207). Deve-se ainda acrescentar, sob esta perspectiva, que a cidade da expansão da indústria e do comércio e da ordem civilizada contrastava com o crescimento desordenado e descontrolado da multidão de pobres que habitava Londres.

Thompson também considerou o significado do que é "escriturado", no poema, relacionado-o ao comércio e para ele a alusão é clara e vai além: relacionava-se às companhias oficiais, consideradas como privilégios dentro do governo da cidade. Associavase, também, ao monopólio da Companhia das Índias Ocidentais no comércio através do Tâmisa, que foi renovado por mais de 20 anos e duramente atacado pelos reformistas (THOMPSON, 1994, p. 176).

Os contrastes entre riqueza e pobreza existiam no campo, porém, a contradição se transformou na marca da cidade, onde "[...] As lojas desonestas, os bordéis e as casas de cômodos, os porões fétidos e os cortiços perigosos eram parte importante da imagem formada pelo observador estrangeiro ou de classe média [...]" (WILLIAMS, 1989, p. 203). Ao fazer referência aos trabalhadores era comum a utilização, pela classe média, de termos como a "ralé insolente", a "insolência da turba", a "indolência, dissipação e devassidão" dos trabalhadores. O crescimento acelerado da cidade, e a consequente concentração populacional, tornavam os contrastes entre riqueza e pobreza não apenas mais claros como também mais intensos. É preciso ressaltar o fato de que entre 1700 e 1820 a população de Londres atingiu, pela primeira vez na história, 1.200.000 habitantes. Londres, enquanto

\footnotetext{
${ }^{12}$ [...] A charter of liberty is, simultaneously, a denial of these liberties to others. A charter is something given or ceded; it is bestowed upon some group by some authority; it is not claimed as of a right. And the liberties (or privileges) granted to this guild, company, corporation or even nation exclude others from the enjoyment of these liberties. A charter is, in its nature, exclusive.

${ }^{13}$ I wander thro each dirty street / Near where the dirty Thames does flow.
} 
capital, como que resumia a imagem do país como um todo, mostrando todo o desenvolvimento de uma sociedade em termos industriais, seus desdobramentos e contradições.

Para Blake, todas as restrições do espaço urbano são generalizadas e encontradas numa repressão que é tanto externa quanto interna ao homem. Ele expressou esse pensamento na segunda estrofe do poema, ao se referir às "algemas forjadas pela mente": "Ouço nos gritos que os adultos dão, / E nos gritos de medo do inocente, / Em cada voz, em cada interdição, / As algemas forjadas pela mente". A ordem humana e social é vista como um todo que se mostra como fraqueza e sofrimento. Dessa forma, podemos compreender que essas "algemas forjadas pela mente" são compostas pela derrota, o interesse egoísta, a ausência do amor, a lei, a repressão e a hipocrisia, além disso, elas aprisionam não apenas as mentes dos opressores, como também dos oprimidos, sendo auto forjadas (THOMPSON, 1994, p. 184). ${ }^{14}$

O desafio de Blake sugerido no poema seria também reclamar direitos universais, se inserindo, dessa forma, na discussão política que agitava a Inglaterra entre os anos de 1791 e 1793, especialmente aquelas que ocorreram entre Thomas Paine e Edmund Burke. Se os trabalhos de Edmund Burke foram constituídos de uma defesa do conservadorismo, podemos considerar Direitos do Homem de Paine como um dos textos de fundação do movimento operário inglês, escrito sobre a condição inglesa e contaminado pelas novas ideias americanas e francesas, no qual o autor enumerou, o tratamento diferenciado sobre as classes proprietárias e não-proprietárias.

A palavra charter'd utilizada por Blake em London remete de maneira mais profunda às questões levantadas através das propostas e críticas expostas na segunda parte de Direitos do Homem, na qual Paine condena instituições e corporações que levam a anulação dos direitos da maioria. Mas outros temas ainda merecem ser apontados em London. David Erdman, por exemplo, fez algumas considerações a respeito do aparecimento da figura do "soldado", nos versos: "Se o Soldado suspira de desdita, / O sangue mancha os muros palacianos". Para o autor o aparecimento do soldado, bem como das "algemas" no poema de Blake são um indicativo da aliança Britânica com a Prússia e Áustria contra a França (ERDMAN, 1954, p. 256). Ele chama a atenção para o fato de que Songs of Experience só seria publicada no momento em que a Inglaterra adentrava numa nova campanha, depois da guerra americana.

O soldado cujo sangue "mancha os muros palacianos" é uma vítima infeliz, apesar de ser parte de um estado armado. $O$ destino de um soldado na década de 1790 era complicado, pela disciplina e punições impostas. O soldado, que "suspira de desdita", metaforicamente mancha

\footnotetext{
${ }^{14}$ [.].The 'mind forg'd manacles', then are those of deceit, self-interest, absence of love, of law, repression and hipocrisy. [...] they bind the minds not only of the opressors but also of the opressed; moreover, they are selfforged. [.].
} 
as paredes do palácio com o seu sangue, assim como o grito do limpador de chaminés "assusta a Igreja escura" (KORNER, 2008). ${ }^{15}$

Devemos ressaltar aqui também o fato de que a adesão de Blake às ideias republicanas pautava-se, principalmente, em argumentos religiosos. Nas leituras bíblicas dos dissidentes radicais e de Blake, que foram utilizadas como um instrumento de crítica social, destacamos os livros proféticos de Isaías, Ezequiel e do Apocalipse. No poema London destacamos a analogia entre algumas ideias encontradas no livro do apocalipse. As analogias bíblicas de Blake no poema são encontradas principalmente em duas passagens do livro do Apocalipse de São João, no capítulo 13:

A segunda Besta faz também com que todos, pequenos e grandes, ricos e pobres, livres e escravos, recebam uma marca na mão direita ou na fronte. E ninguém pode comprar nem vender se não tiver a marca, o nome da Besta ou o número do seu nome. Aqui é preciso entender: quem é esperto, calcule o número da Besta; é um número de homem; o número é seiscentos e sessenta e seis. (APOCALIPSE 13, 16-18)

E também no capítulo 14:

Apareceu um segundo anjo e continuou: "Caiu, caiu Babilônia, a Grande. Aquela que embebedou todas as nações com o vinho do furor de sua prostituição." Apareceu um terceiro Anjo e continuou em alta voz: "Se alguém adora a Besta e a imagem dela, e recebe sua marca na fronte ou na mão, esse também vai beber o vinho do furor de Deus, derramado sem mistura na taça da sua ira. Será atormentado com fogo e enxofre diante dos santos Anjos e diante do Cordeiro. A fumaça do seu tormento subirá para sempre: os que adoram a Besta e a imagem dela, e quem quer que receba a marca do seu nome, nunca têm descanso, nem de dia, nem de noite..." (APOCALIPSE 14, 8-11)

Uma ênfase é dada a palavra "sinais" [Mark] na primeira estrofe do poema, onde ela se repete por três vezes no poema original [And mark in every face I meet / Marks of weakness, marks of woe.]. Estes "sinais", ou marcas, são um indício da forma como Blake enxergava a sociedade londrina, que para ele seria uma sociedade apocalíptica. As inúmeras referências ao Anticristo no interior da dissidência do século XVIII, à Besta e aos "adoradores de sua imagem" são um ponto de convergência entre a obra de Blake e seu significado religioso,

15 The soldier whose sigh "Runs in blood down Palace walls" is a "hapless" victim, in spite of the fact that he is part of the armed state. A soldier's lot in 1792 was terrible, with violent discipline and punishment. [...] The soldier, sighing in death or fear, metaphorically stains the palace walls with his blood just as the sweep's cry blackens the churches. 
indicando a origem dos "sinais" aos quais o poeta se referiu. O radicalismo social equiparou aqueles que recebiam o "sinal" aos que praticavam a usura, aos ricos, bem sucedidos em comprar e vender. A interpretação milenarista do Apocalipse tornou-se marcante a partir da década de 1790, particularmente entre os Swedenborgianos, e a obra de Blake, assim como o pensamento de dissidentes radicais foram saturadas de imagens apocalípticas. As críticas aos reis, falsos profetas e ricos encontradas nos capítulos do Apocalipse, na alusão à imagem da Besta e da destruição da Babilônia, foram muito comuns no interior da dissidência como elementos que os pobres agregaram às suas reivindicações e protestos contemporâneos (THOMPSON, 1994, p. 182). A imagem relacionada ao poema, que reproduzimos a seguir, também complementa o seu significado:

Figura 1 -London, de Songs of Experience, c. 1826

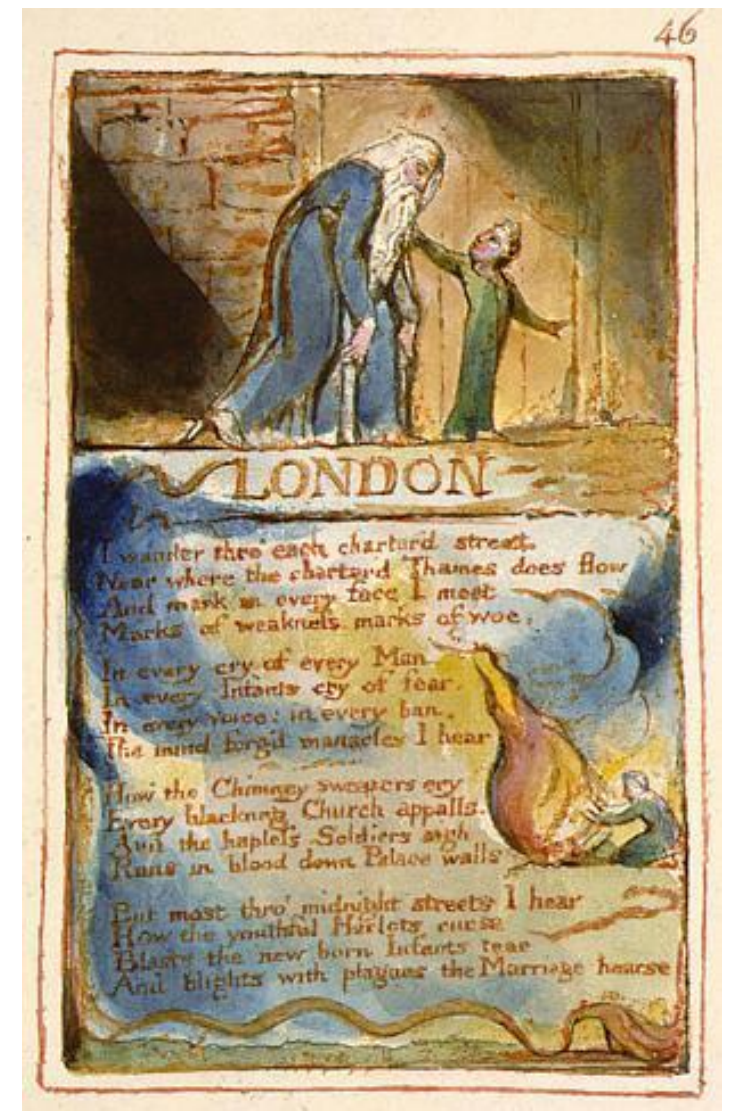

Copy AA, object $46^{16}$ 
Os seguintes versos de Jerusalem (livro 4) esclarecem também o significado da imagem e parecem na verdade descrevê-la, e são mais um indicativo das simbologias apresentadas no poema: Eu vejo Londres cega \& definhando, mendigando pelas Ruas / Da Babilônia, conduzida por uma criança, suas lágrimas escorrem por sua barba. (BLAKE, In: ERDMAN, 1988, p. 243) ${ }^{17}$

David Erdman chamou a atenção para a intertextualidade entre London e Jerusalem. Na ilustração observamos um menino, na parte inferior à direita da gravura, que pode ser comparado ao "pequeno vagabundo" retratado em outro poema de Songs of Experience, que também é retratado aquecendo suas mãos ao lado de uma fogueira. Na parte superior da página um garoto guia pela calçada um homem idoso de barba longa, pés descalços, que se apoia em muletas, eles caminham ao lado de uma porta fechada. Erdman apontou que em Jerusalem Blake também retratou um homem idoso, que denominou London, sendo guiado de forma similar próximo a uma porta aberta. Na gravura acima, Erdman indica que um feixe de luz ilumina o menino e o homem idoso apontando, para ambos, conforto e salvação em relação dos "gritos de medo". O velho retratado na gravura pode ser também Urizen, que na mitologia blakeana é o senhor do tempo, dos limites, da razão e das leis morais. Este personagem pode ser considerado também o responsável pelas "algemas forjadas pela mente", cujas característas se assemelham à representação do personagem (ERDMAN, 1992, p. 88).

Para Erdman, a referência bíblica dos "sinais" no poema apontaria para a salvação dos homens (ERDMAN, 1992, p. 88) e não deveríamos associá-la ao livro do Apocalipse, mas sim à seguinte passagem de Ezequiel:

Javé falou com ele: "Percorra a cidade de Jerusalém e marque com uma cruz a testa dos indivíduos que estiverem se lamentando e gemendo por causa das abominações que se fazem no meio dela" (EZEQUIEL 9, 4).

Vê-se que não existe uma interpretação única e consensual sobre o tema entre os estudiosos, tanto que Thompson discorda desta versão, pois, segundo ele, uma observação literal não se encaixa no significado do poema. As "marcas" (sinais) narradas por Blake no poema não são de lamentações e abominações, mas de fraqueza e dor, portanto, diferente da referência buscada em Ezequiel, onde apenas alguns homens receberam uma marca em sua fronte. No poema, assim como nas passagens citadas do Apocalipse todos haviam recebido a marca e, conforme considerou Blake, elas estavam "em todo rosto encontrado" [mark in every face I meet]. Diverge também de Ezequiel o destino dos homens marcados, pois neste livro

\footnotetext{
${ }^{17}$ I see London blind \& age-bend begging through the Streets / Of Babylon, led by child, his tears run down his beard.
} 
eles foram marcados para sua salvação, enquanto no Apocalipse a marca representava a danação, encaixando-se melhor na concepção blakeana sobre a cidade. Assim, considerandose o contexto cultural do século XVIII e as inúmeras referências religiosas ao Apocalipse, parece ser improvável a possibilidade dos versos de Blake serem uma alusão a Ezequiel.

Thompson considerou também que a alusão à Marca da Besta no poema representou algo próximo das ruas e do Tâmisa "escriturados", sendo ambos relacionados à ideia de compra e venda de valores humanos (THOMPSON, 1994, p.180). Ainda segundo Thompson, o soldado, no poema, seria também um indicador da consumação apocalíptica da cidade ou mesmo de uma transformação revolucionária (THOMPSON, 1994, p. 192). Entretanto, uma observação deve ser feita aqui: a cidade de Londres não pode ser considerada simplesmente como uma reprodução da visão apocalíptica na obra de Blake. Ela possui um significado mais amplo. É a cidade da "inocência perdida" e, sob influência de um pensamento Swedenborgiano, também a cidade do advento do milênio.

Por fim, é preciso observar que a prostituta representada nos últimos versos do poema não pode ser apenas um símbolo religioso. É possível que ela também simbolize a culminante reificação dos valores na sociedade industrial: Mas o que mais à meia noite é ouvido / É a rameira a lançar praga fatal, / Que estanca o pranto do recém nascido / E empesteia a mortalha conjugal. Sendo aquela que compra e vende o seu amor, a prostituta "[...] não apenas fornece um símbolo culminante da reificação dos valores, ela é também um ponto de junção com uma imagética paralela de mistificação religiosa e opressão [...]" (THOMPSON, 1994, p. 191) ${ }^{18}$ Ela marca a separação entre corpo e alma, ou da subjetividade e a vida espiritual que se rende à vida material.

O seu filho, por sua vez, é um resultado de comércio, não de amor, e sua existência marca um sofrimento crescente. Ela passa a sua maldição para o seu filho que por sua vez o transmitirá às gerações futuras. A sua maldição, como o grito do limpador de chaminés, e o lamento do soldado, tem efeitos visíveis (KORNER, 2014). ${ }^{19}$

A prostituta que aparece no poema é associada também à prostituta da Babilônia, que Blake também retratou em uma de suas gravuras, intitulada The Whore of Babylon, reproduzida a seguir:

\footnotetext{
${ }^{18}[\ldots]$ not only provides a culminating symbol of the reification of values, she is also a point of junction with the parallel imagery of religious mystification and oppression [...].

${ }^{19}$ She has been robbed of the chance to love her baby, because it is the result of commerce, not love, and because its existence only brings her increased penury. She passes her own misery onto her child, and that child, like her, will pass its misery onto further generations. [...] Her curse, like the sweep's cry and the soldier's sigh, has actual effects.
} 
Figura 2 The Whore of Babylon, c. 1809

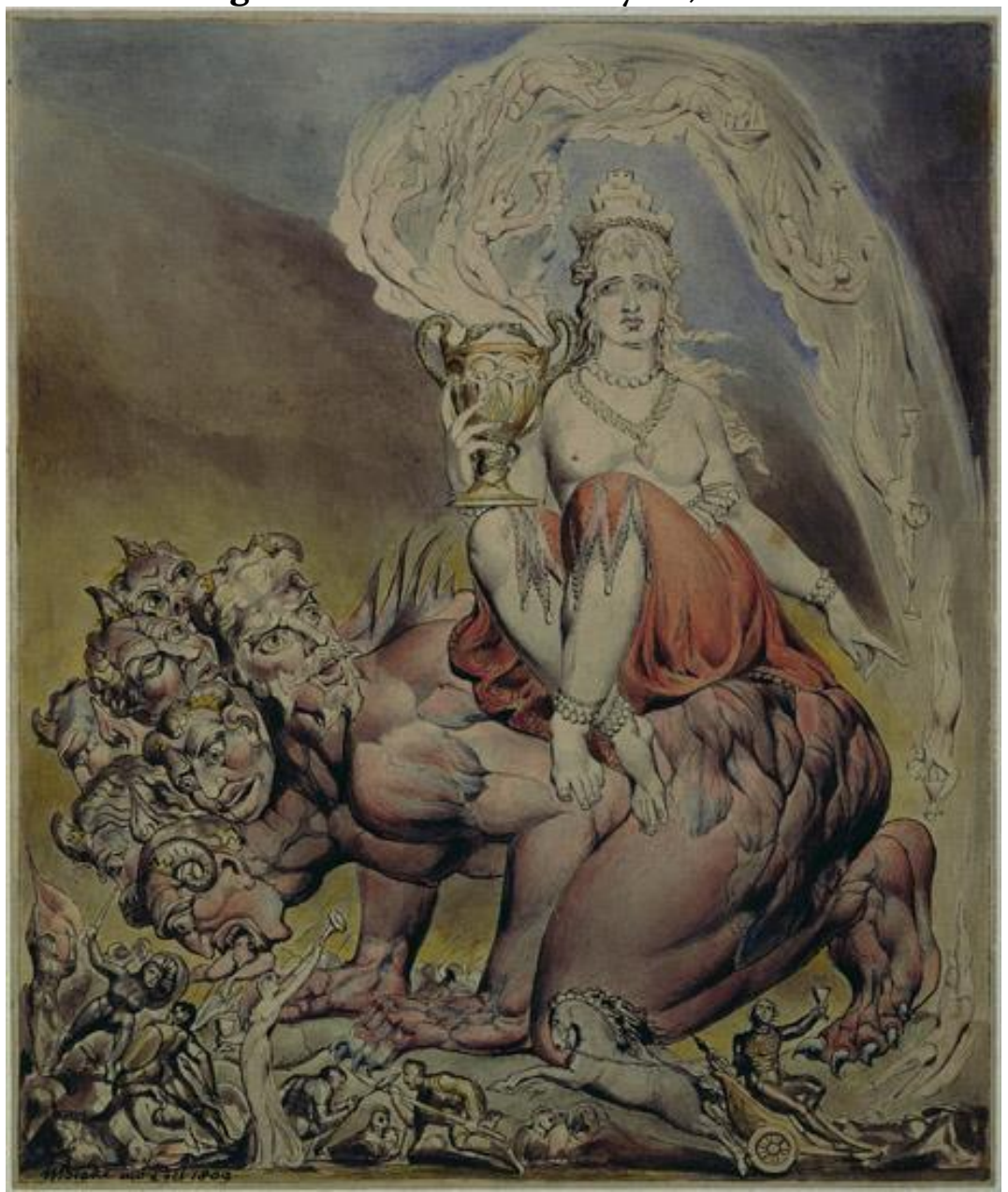

Fonte: Pintura produzida para Thomas Butts em $1809^{20}$

Se Londres pode ser considerada como a Babilônia, então Blake retrata no poema a prostituta da Babilônia, que trouxe a destruição da cidade. Essa afirmação pode ser sustentada se levarmos em contra outras afirmações de Blake feitas alguns anos depois de escrever London, quando disse que "defender a Bíblia neste ano de 1798 custaria a vida a um homem"; "A Besta e a Prostituta governam sem controle". De acordo com Apocalipse 14, ela "embebedou todas as nações com o vinho do furor de sua prostituição", indicando, dessa forma, um estado de reificação generalizada na sociedade inglesa.

Para a dissidência radical inglesa, a prostituta da Babilônia representava também a "mulher escarlate" de Roma, simbolizando todo compromisso entre uma instituição supostamente espiritual e os poderes temporais do Estado, associando-se especificamente à Igreja Anglicana. Desse modo, “[...] a prostituta é capaz de unir num único símbolo a imagem

\footnotetext{
${ }^{20}$ Imagem disponível em: http://www.blakearchive.org/ acesso em 17/02/2014.
} 
das relações de mercado e a imagem da dominação ideológica pela atividade de uma Igreja Estatal, prostituída pelas causas do poder temporal. [...]" (THOMPSON, 1994, p. 192). ${ }^{21}$

A separação entre corpo e alma é apontada em The Marriage of Heaven and Hell e também é capaz de elucidar o aparecimento da prostituta no poema London. Para Blake, as religiões seriam causadoras dos seguintes erros; "Que o homem tem dois princípios existentes reais, a saber: um Corpo \& uma Alma" e "Que a Energia, chamada Mal, é apenas do Corpo, \& que a Razão, chamada Bem, é apenas da Alma" e ainda "Que Deus atormentará o homem pela Eternidade por seguir suas Energias". Uma das afirmações que se contrapõe às anteriores é a de que "O Homem não tem corpo distinto de sua Alma, pois o que é chamado Corpo é uma porção da Alma discernida pelos cinco Sentidos, os condutos principais da alma nesta era". Sua crítica se baseia no pensamento de que a alma, para as religiões tradicionais, seria mais nobre que o corpo. No entanto, "[...] Se o corpo é a alma vista da perspectiva deste mundo, é fácil ver o quanto é devastadora essa negação daqueles simples desejos que são necessidades imaginativas. [...]" (FRYE, 1990, p. 74). ${ }^{22}$

A supremacia da alma no interior da religião é interpretada por Blake também como a supremacia de uma única doutrina e para ele o que é chamado mal, o corpo e os desejos seriam a verdadeira sede da capacidade imaginativa e seu poder libertador. Os dogmas da Igreja são "algemas" para o homem e parte do mesmo processo no qual o corpo é separado da alma e onde o mundo vegetativo (material) sobrepuja o verdadeiramente espiritual (FRYE, 1990, p. 74).

Com as considerações de The Marriage of Heaven and Hell, Blake aponta a transição da lei mosaica para a lei do amor, que marcam também a transição do velho para o novo olhar de Deus representado nos Evangelhos. Os milagres descritos nos Evangelhos são um trabalho tanto de visão quanto de vontade, e ilustram o poder da imaginação sobre o mundo da experiência.

De acordo com Frye, a prostituta tipifica de maneira próxima cada aspecto da vida do homem decaído, e o perdão de Jesus para a prostituta é a forma real de quem a Prostituta do Apocalipse é a analogia. Blake entende o perdão como a libertação do poder imaginativo, a criação de condições que possibilitam a verdadeira eliminação do pecado. Dentro da vida moderna, os ensinamentos dos evangelhos indicam que os diversos "melhoramentos" implantados na civilização devem ser associados a um correspondente progresso da visão que indicará como usá-los (FRYE, 1990, p. 393).

\footnotetext{
${ }^{21}[\ldots .$.$] the harlot is able to unite in a single nexus the imagery of market relations and the imagery of$ ideological domination by the agency of a State Church, prostituted to the occasions of temporal power.[...]

${ }^{22}$ [...] As the body is the soul seen from the perspective of this world, it is easy to see how murderous this denial of those simple desires which are imaginative needs must be. [...]
} 
A compaixão assinalada por Blake seria sobre os homens que estavam imersos na sociedade que ele considerou como um "inferno" sobre os sofredores, enquanto o tom de indignação versa sobre as instituições de repressão, assinaladas no poema pelas "algemas forjadas pela mente", a "Igreja escura", o "Palácio", a "mortalha conjugal", ao passo que a organização simbólica da cidade é concebida dentro da lógica das relações de mercado que então se desenvolviam.

Em London, há outro personagem que merece destaque, representando a questão do trabalho infantil durante a Revolução Industrial nas "canções" de Blake: o limpador de chaminés. O menino que "apavora cada Igreja escura" com seu lamento no poema é um indicativo, segundo Thompson, de que "[...] numa única linha, o adjetivo 'escura' ataca visualmente a complacência da Igreja com a exploração brutal de crianças junto às maiores consequências da fumaça do comércio em expansão [...]"(THOMPSON, 1994, p. 185). ${ }^{23}$ Os versos de London sobre o limpador de chaminés que "apavora cada igreja escura com seu grito" também pode ser considerado um comentário sobre o despertar da consciência social das Igrejas sob influência da revivificação evangélica. Percebemos que o limpador de chaminés é mencionado em London como parte integrante do quadro geral da sociedade londrina, mas Blake enfatizou seu papel, e tudo que ele representou nos poemas homônimos The Chimney Sweeper.

O que percebemos no poema London como um todo é que o homem preso à razão, à ordem política, religiosa e econômica foi representado como uma mercadoria. Isto é o que foi simbolizado pelos diferentes personagens do poema, como o limpador de chaminés, o soldado e a prostituta.

É possível dizer que através do limpador de chaminés, que é retratado não apenas no poema London como também nos poemas homônimos The Chimney Sweeper, William Blake condensou os significados de Inocência e Experiência. Os românticos associaram a infância à inocência e Blake retratou diversas crianças em suas canções da inocência, dentre elas, os meninos limpadores de chaminés. Esses garotos, porém, devido às condições de trabalho penosas às quais eram submetidos conheceriam precocemente o universo da experiência, associado ao mundo adulto no qual o homem adquire o conhecimento dos seus limites, do sofrimento, e se torna consciente acerca da natureza da morte. E. P. Thompson considerou que ocorreu um aumento substancial da exploração do trabalho infantil entre os anos de 1780 e 1840 e podemos indicar, como algumas das funções mais penosas desempenhadas por crianças, o trabalho dos garotos empregados em navios e dos limpadores de chaminés, sendo que essas ocupações poderiam ser consideradas ainda piores do que qualquer tipo de função exercida nas primeiras fábricas (THOMPSON, 2004, v.2, pp. 202-203). Esses meninos enfrentavam, em função de seu ofício, vários problemas de

${ }^{23}$ [.].into a single line, the adjective blackning' visually attaching to the Church complicity in the brutal exploitation of young childhood along with the wider consequences of the smoke of expanding commerce. 
saúde e deformidades permanentes como: a torção da rótula de seus joelhos, a espinha e os tornozelos que também ficavam deformados e a fuligem lhes causava inflamações nos olhos e doenças respiratórias, dentre outros problemas de saúde, devido a esses problemas ou mesmo à falta de instrução para o desempenho de outras atividades esses meninos se tornavam inaptos para o trabalho quando cresciam e muitos deles eram cuidados por casas de caridade mantidas pelas Igrejas, é por isso também que o limpador de chaminés assusta a "Igreja escura" por mostrar a sua complacência com a exploração das crianças.

Esses valores religiosos representavam "algemas forjadas pela mente", que também são associadas à disciplina imposta aos soldados e à venda do amor da prostituta. Nesse sentido, a transformação religiosa apontada pelo evangelho, conforme vista pelas dissidências religiosas do século XVIII, transformaria o papel da Igreja e os seus valores morais, do mesmo modo que transformariam o soldado que tomaria consciência das algemas mentais às quais estava submetido e a prostituta que não mais comercializaria o que não deveria ser comercializado: o seu corpo, o amor e, tendo em vista que Blake não considerava o corpo como algo separado da alma, a própria alma.

A prostituta retratada por Blake e a sua associação com imagens apocalípticas, indica a visão de Blake acerca dos valores em ascensão na sociedade industrial inglesa, ela mostra a reificação humana generalizada naquela sociedade através da venda de valores imateriais. Para Blake, os homens da cidade de Londres seriam egoístas, e cegos forjavam as algemas que prendiam a si mesmos e aos outros, nesse novo mundo não era apenas o trabalho que era objeto de comércio, mas também o amor, o tempo, a própria vida.

London começa com a referência ao sistema econômico, trabalhado a partir da palavra legalista "charter'd", que é percebida "em cada voz, em cada interdição". Então, o poema parte para os desdobramentos desse sistema econômico, a venda de corpos e almas num sistema fechado de exploração econômica. Diante disto, parece ser possível sugerir que Blake, nesse trabalho, não teve como objetivo apenas "catalogar infortúnios", mas através da ordem dos encontros, ele procurou revelar as suas interconexões e desdobramentos.

\section{Fontes}

BÍBLIA. Português. Tradução de Ivo Storniolo, Euclides Martins Balancin e José Luís Gonzaga do Prado. São Paulo: Sociedade Bíblica Católica Internacional e Paulus Ed.,1990.

BLAKE, William (1757-1827). William Blake: poesia e prosa selecionadas/ Edição bilíngüe. Introdução, seleção, tradução e notas Paulo Vizioli. São Paulo: Nova Alexandria, 1993.

ERDMAN, David V. (ed.). The Complete Poetry and Prose of William Blake. New York: Anchor Books, 1988. 
(ed.). The Illuminated Blake: William Blake's Complete Illuminated

Works with a Plate-by-Plate Comentary by David V. Erdman. New York: Dover Publications, 1992.

\section{Bibliografia}

ALVES, Andréa Lima. “A Oposição é Verdadeira Amizade”: Imagem poética e pictórica no livro $O$ Matrimônio do Céu e do Inferno de William Blake. Campinas-SP, 2001. 216 p. Dissertação de Mestrado. Universidade Estadual de Campinas, Instituto de Estudos da Linguagem.

ALVES, Andréa Lima. A interação entre texto e ilustração nos illuminated books de William Blake sob o prisma da obra America: A Prophecy. Campinas-SP, 2007. 274 p. Tese de Doutorado. Universidade Estadual de Campinas, Instituto de Estudos da Linguagem.

BAUMER, Franklin L. “O Mundo Romântico”. In: O Pensamento Europeu Moderno, $2^{\circ}$ volume. Tradução de Maria Manuela Alberty. Lisboa: Edições 70, Lda., 1990.

EAVES, Morris; Robert N. Essick \& Joseph Viscomi (eds.). The William Blake Archive. http://www.blakearchive.org

ERDMAN, David V. Blake: Prophet Against Empire. Princeton: Princeton University Press, 1954.

FRYE, Northrop. Fearful Symmetry. Princeton: Princeton University Press, 1990.

HILL, Christopher. A Revolução Inglesa de 1640. Tradução de Wanda Ramos. Lisboa: Presença, 1985.

O Mundo de Ponta-Cabeça: idéias radicais durante a revolução

Inglesa de 1640. Tradução de Renato Janine Ribeiro. São Paulo: Companhia das Letras, 2001.

A Bíblia inglesa e as revoluções do século XVII. Tradução de

Cynthia Marques. Rio de Janeiro: Civilização Brasileira, 2003.

HOBSBAWM, Eric. J. Da Revolução Industrial inglesa ao imperialismo. Tradução de Donaldson Magalhães Garschagen. Rio de Janeiro: Forense Universitária, 2009.

KORNER, Simon. William Blake's London. Disponível em:

http://21stcenturysocialism.com/article/william_blakes_london_01594.html Acesso em: $17 / 02 / 2014$.

LINEBAUGH, Peter. Todas mas montanhas atlânticas estremeceram. in Revista Brasileira de História, São Paulo, ANPUH, n. 6, setembro de 1993.

LOURENÇO, Isabel Maria Graça. The William Blake Archive: Da Gravura Iluminada à Edição Eletrónica. Coimbra, 2009. 490 p. Tese de Doutorado. Faculdade de Letras da Universidade de Coimbra, na área de Línguas e Literaturas Modernas. 
LÖWY, Michael. Romantismo e Política. Disponível em:

www.unipam.edu.br/.../RomantismoepolÃtica-MichaelLowy.doc Acesso em: 26/08/2010.

LÖWY, Michael; SAYRE, Robert. Revolta e Melancolia: $O$ romantismo na contramão da modernidade. Petrópolis: Vozes, 1995.

THOMPSON, E. P. (1924-1993). Whitness against the Beast: William Blake and the moral law. New York: The New Press, 1994.

Os Românticos - A Inglaterra na Era Revolucionária. Tradução de Sérgio Moraes Rêgo Reis. Rio de Janeiro: Civilização Brasileira, 2002.

2004 .

A formação da classe operária inglesa. São Paulo: Paz e Terra,

VIGÁRIO, Sílvia Manuela Pereira. Crianças sem Infância: O Trabalho Infantil na Indústria Têxtil e os Limpa-Chaminés (1780-1878). Braga, 2004. 148 p. Dissertação de Mestrado. Universidade do Minho, Instituto de Letras e Ciências Humanas.

WILLIAMS, Raymond. Cultura e Sociedade - 1780-1950. Tradução de Leônidas H. B. Hegenberg Octanny Silveira da Mota e Anísio Teixeira. São Paulo: Companhia Editora Nacional, 1969.

_. Companhia das Letras, 1989. 